\title{
Feminismos en Movimiento, Feminismos en Protesta ${ }^{1}$
}

\section{Feminisms in Movement, Feminisms in Protest}

Sonia E. Alvarez

\section{Resumen}

En este ensayo propongo una gramática político-conceptual, un marco interpretativo para repensar las dinámicas cambiantes de lo que normalmente denominamos "movimientos sociales," haciendo énfasis en los feminismos en movimiento y buscando entender sus recientes expresiones de/en protesta. Mis reflexiones se basan principalmente en mi inmersión en el activismo y la academia feminista en Brasil, así como en el trabajo etnográfico longitudinal y virtual que vengo realizando hace varios años sobre diversos feminismos, movimientos sociales, ONGs, redes de activismo, movimientos antiglobalización, y protestas en la última década en Brasil y otras partes de América Latina.

Palabras clave: Feminismos, Protesta, Racismo, Feminismos negros, Feminismos jóvenes.

\footnotetext{
${ }^{1}$ El presente ensayo fue preparado para el seminario "Actualidad Política de los Feminismos Latinoamericanos," realizado en la Universidad de Chile el 2 y 3 de agosto de 2018. El mismo es fruto de investigaciones teóricas y trabajo de campo llevados a cabo intermitentemente durante los últimos cinco años, principalmente en el Brasil y en algunos espacios transnacionales de activismo feminista. Asimismo, este ensayo desarrolla y actualiza ideas expuestas en Alvarez y Costa (2017), Alvarez (2014), y en un ensayo inédito titulado "Feminism in Movement," el cual presenté como Conferencia Magistral en el Décimo Taller de Teoría Feminista de Duke University el 4 y 5 de marzo de 2016 en Durham, Carolina del Norte. Agradezco a todes les que han contribuido a la evolución, nada linear, de las ideas aquí presentadas, pero en especial a mis colegas/interlocutoras brasileñas de nuevas generaciones, particularmente Laura Martello, Íris Nery do Carmo, Priscila de Carvalho, Viviane Hermida, Ana Carol Ogando, Layla Carvalho y Débora de Fina González. Agradezco a Débora de Fina González por la invitación al seminario y a Martha Balaguera por su ayuda con la revisión de español y por sus inestimables contribuciones a esta y otras de mis investigaciones recientes.

*Leonard J. Horwitz Professor of Latin American Politics and Studies University of Massachusetts, Amherst
} 


\begin{abstract}
In this essay I propose a political-conceptual grammar, an interpretive framework to rethink the changing dynamics of what wenormally call "social movements," emphasizingfeminisms in movement and seeking to understand their recent expressions of / in protest. My reflections are mainly based on my immersion in activism and the feminist academy in Brazil, as well as in the longitudinal and virtual ethnographic work that I have been doing for several years on various feminisms, social movements, NGOs, activism networks, anti-globalizationmovements, and protests in the last decade in Brazil and other parts of LatinAmerica.
\end{abstract}

Keywords: Feminisms, Protest, Black Feminisms, Racism, Young Feminisms.

Fecha de recepción: Abril 2019

Fecha de aprobación: Junio 2019

\title{
Introducción
}

Mi objetivo aquí estratar de superar los ya cansados debates sociológicos sobre "flujo y reflujo", o ascenso y descenso cíclico de la protesta y los movimientos sociales para proponer formas alternativas de teorizar los interminables debates que se dan entre feministas activistas y académicas sobre cuál es el "estado del movimiento." ¿Está saludable, alcanzando su auge, retrocediendo, en suspensión? ¿Se encuentra institucionalizado, ha sido cooptado, continúa autónomo? ¿Es subversivo o ha sido disciplinado? ¿Está siendo efectivo y exitoso, o ha entrado en declive?

Mi esfuerzo de revisión teórica sigue las pistas interpretativas de la historiadora feminista estadounidense Anne [Finn] Enke (2007) y la teórica feminista británica Clare Hemmings (2011). "Localizar al activismo feminista" es la tarea central que Enke se propone en Finding the Movement: Sexuality, Contested Space, and Feminist Activism (2007). En este texto, la historiadora descubre que "el movimiento tuvo lugar afuera y al lado, así como dentro de instituciones y actoras con el nombre 'feminista". Ella se pregunta: "¿Qué pasaría con la historia del feminismo si miráramos más allá de los archivos del ya conocido y presunto sujeto feminista?" (Enke 2007, 4). Su propuesta consiste en "repensar los parámetros del feminismo" en los años sesenta y setenta en los Estados Unidos para abarcar ligas de softball, parques públicos, librerías para mujeres, bares lésbicos, refugios para mujeres en situaciones de violencia, clínicas de salud, y otros espacios más allá de lo que normalmente se considera como el 'feminismo organizado"'(12). Los parámetros del feminismo y sus actoras eran entonces y continúan siendo hoy bastante diferentes en el Brasil, pero la pregunta de Enke resulta extremadamente pertinente para el sur de las Américas porque apunta a la necesidad de una nueva óptica a través de la cual "buscar al feminismo" más allá de las actoras y 
lugares con que convencionalmente lo asociamos, y analizarlo en proceso, mientras se mueve y se reconfigura continuamente, propulsado por cambios, tensiones y contradicciones internas y por transformaciones en el entorno más amplio en el que se inserta.

Recalibrar nuestros lentes analíticos también implica, siguiendo a Clare Hemmings (2011), contar historias o cuentos sobre el feminismo de manera diferente (telling feminist stories otherwise). Preguntarnos qué está en juego políticamente en el contar esas historias y más importante aún, tratar de intervenir en esos cuentos, como ella sugiere, para "realinear nuestra gramática política y permitir una visión diferente del pasado, presente y futuro feminista" (2011, Kindle Locations: 62-64). En sus palabras, se trata de "interrumpir las versiones prevalecientes de las narrativas que componen las historias feministas occidentales dominantes y contar historias de manera diferente" (idem, 74).Al ampliarlos lentes analíticos a través de los cuales busco a los feminismos y, por lo tanto, al re-visualizar sus parámetros y trayectorias históricas, pretendo analizar, al igual que Hemmings, "no tanto qué otra historia más verdadera podríamos escribir, sino la política que produce y sostiene una versión de la historia como más cierta que otra, a pesar de que sabemos que la historia es más complicada que las historias que contamos sobre ella" (Kindle Locations: 322-325).

Entonces, los cuentos que quiero compartir no tratan sólo de cómo se han movido los feminismos en Brasil y en otras partes de América Latina, sino que intentan ilustrar cómo la realineación de nuestra gramática conceptual y política puede permitirnos ver y entender a los feminismos de manera diferente. Cómo y dónde tratamos de encontrar el feminismo en movimiento inevitablemente afecta cómo podemos imaginarlo, teorizarlo y, por lo tanto, practicarlo. Ésa, para mí, es la apuesta teórica y política que implica revisar las concepciones que prevalecen sobre lo que acostumbramos a llamar "el" movimiento feminista.

La gramática que propongo para analizar las dinámicas cambiantes del activismo feminista gira en torno a dos conceptos claves: "campos discursivos de acción" y "assemblages" o "ensamblajes activistas." El primer concepto es de cuño propio y lo vengo retrabajando y readaptando a lo largo de algún tiempo. El segundo, assemblage, que es de difícil traducción al español, proviene de varias corrientes teóricas: Deleuze y Guattari, la teoría de actor-red, los estudios de ciencia y tecnología, y el autonomismo marxista a-la Hardt y Negri, como sugieren Janet Conway, Michal Osterweil y Elise Thorburn (2018). Lo traduzco aquí como ensamblaje. La idea de assemblage "busca reforzar la relevancia de la agencia, del actuar, por medio del cual elementos heterogéneos son colocados en relación, simultáneamente transformándose, transformando lo que los reúne y, al final, transformando lo que los rodea" (Carvalho 2018, 95-96). Buscaré en diversos tratamientos teóricos de assemblage una óptica que nos pueda ayudar a mejor aprehender, empíricamente, las dinámicas del activismo feminista "callejero" que venimos presenciando a nivel regional y global en la última década. Pero, antes que nada, explico cómo llegué a estas ópticas particulares para "ubicar" al activismo feminista, relatando observaciones de tres momentos distintivos de mi extenso trabajo de campo. 


\section{Observaciones de Campo y Conceptualizaciones sobre Campos}

Un primer momento crucial, que originalmente me inspiró la idea de campo feminista, fue mi participación en los procesos preparatorios de Brasil y, a nivel regional, de América Latina para la Conferencia de Beijing (la Cuarta Conferencia Mundial sobre la Mujer) desde principios hasta mediados de los años noventa ${ }^{2}$. Al observar el avance de ese proceso durante más de dos años, comencé a reconcebir el llamado movimiento feminista, una categoría hasta entonces típicamente circunscrita a un grupo relativamente pequeño de mujeres, en su mayoría euro-descendientes, de clase media, con educación universitaria, quienes declaraban estar comprometidas con lo que eran llamadas de cuestiones "específicas" de las mujeres —como el aborto, la violencia doméstica, y la sexualidad-, a la vez que adherían a lo que en la década de los setenta en América Latina le llamaban la "lucha general" por la transformación social y contra la autoritarismo militar instalado en el Brasil en 1964 y propagado por casi toda la región a partir de los 1970.

A lo largo del proceso de Beijing, observé que ese "movimiento feminista" parecía haberse transformado en un "campo de acción" cada vez más amplio, más heterogéneo y más disperso en términos espaciales durante las décadas de los ochenta y noventa, época en la que el feminismo se movió, se articuló en y con otros espacios, otros movimientos sociales, partidos e instituciones nacionales e internacionales (como la $\mathrm{ONU}$ ), y pasó por un proceso al cual me referí como decentering o descentramiento, que fue a la vez causa y consecuencia de que el género se convirtiera cada vez más en un temaen la formulación de políticas públicas nacionales y globales (Alvarez 2001).

Con el retorno de gobiernos civiles a muchos países de la región y la entrada de algunas feministas antes ligadas a la oposición a instituciones dominantes, proliferaron acaloradísimos debates sobre si una activista que pasó a trabajar dentro del gobierno, por ejemplo, seguía siendo o no parte "del movimiento". Empecé a considerar que quienes se planteaban la pregunta de quién legítimamente pertenecía o no al feminismo ya estaban involucradas en lo que comencé a conceptualizar como campo feminista. Es decir, la articulación de ese campo parecería darse no sólo mediante vínculos organizativos sino también de forma discursiva, pues las actoras que en él circulaban compartían y al mismo tiempo continuamente disputaban un universo de referentes y significados sobre lo que era o no era el feminismo, la opresión de las mujeres, la desigualdad entre hombres y mujeres, etcétera. Con base en esta observación, decidí añadir el calificativo "discursivo" a la noción de campo de acción, concepto que deduje en aquel entonces podría dar cabida a lo que algunas analistas más tarde denominaron "activismo [feminista] institucional", insertado en el aparato del Estado o en las instituciones internacionales (Abers y Tatagiba 2015; Banazak 2010). Además, éste daba cuenta de aquellas

\footnotetext{
2 Tuve una oportunidad única de acompañamiento cercano y extensivo a estos procesos, pues en la época de Beijing estaba de licencia de la universidad trabajando como asesora del programa de derechos y justicia social de la Fundación Ford en Rio de Janeiro entre 1993 y 1996. Esta posicionalidad me proporcionó un acceso extraordinario, a la vez que me limitó la entrada a algunas discusiones estratégicas entre activistas.
} 
feministas (la abrumadora mayoría) que continuaron participando principal 0 exclusivamente en lugares más convencionalmente entendidos como propiamente "del movimiento."

El término "campo" también formaba parte de una gramática interna del activismo. Algunas activistas brasileñas se referían a sí mismas como integrantes de campos políticos específicos en el interior del feminismo, tales como el "campo anticapitalista." Otras, algunas de quienes entrevisté a finales de los noventa en Chile, igualmente hablaban de "marcar la cancha" entre las "institucionalizadas" y las "autónomas" dentro del "campo feminista". Mis primeras conceptualizaciones teóricas sobre esa idea, entonces,se inspiraron no en Bourdieu (1993) u otros teóricos del Norte Global como McAdam y Fligstein (2012), quienes han teorizado los "fields" o "campos," sino en un lenguaje propio del feminismo y en formulaciones académicas elaboradas por activistasintelectuales brasileños como Eder Sader (1988), Sergio Baierle $(1992,1998)$ y Ana Maria Doimo (1995). Doimo argumenta, por ejemplo, que en las décadas de los setenta y ochenta, los movimientos populares del Brasil actuaban "dentro de un campo éticopolítico", constituido por la "existencia de una sociabilidad común que surge del sentimiento de pertenencia a un espacio compartido de relaciones interpersonales y atributos culturales, a partir de signos de lenguaje, códigos de identificación, creencias religiosas, etc." (1995, 68).

El movimiento feminista, ponderé, también podía entenderse mejor como un campo en el sentido de Doimo; aquellas que se identificaron como feministas compartían sentimientos de pertenencia, incluso cuando no eran miembros "de carné" de una organización o red feminista legitimada como tal. Esta identificación prevalecía a pesar de que les fuera negada la inclusión en "el feminismo" por actoras hegemónicas, como veremos en un momento. "Compartían códigos de identificación" incluso cuando estaban situadas en espacios sociales, como partidos políticos o sindicatos, que, en los términos de Enke, están "afuera y al lado ... de instituciones y actoras con el nombre 'feminista."

Ahora vamos a mi segunda "meta-observación" de/sobre los campo(s): durante la primera mitad de la década del 2000 , seguí los viajes de las ideas y prácticas feministas en el Brasil desde y hacia una amplia gama de agrupaciones feministas y otros espacios paralelos en la sociedad civil, lo que resultó en una expansión horizontal y pluralización dramática del campo feminista. Esto me llevó a desarrollar la idea del side streaming feminista, para llamar la atención analítica a los streams o vertientes, los flujos y entrecruzamientos horizontales de las prácticas y discursos feministas-con sus múltiples traducciones, apropiaciones, y resignificaciones por las más variadas y diversas actoras sociales y políticas-procedentes tanto de espacios "con el nombre feminista" como de otros lugares en la sociedad civil.

Haciendo un juego de palabras (en inglés) con la noción de mainstreaming-que, en el lenguaje de las Naciones Unidas, señalaría el movimiento "vertical" de discursos y propuestas feministas hacia el Estado, los partidos, y otras instituciones dominantes, si se quiere-, la idea de side streaming buscaba arrojar luz sobre los cruces, confluencias y conflictos, casi siempre productivos, entre feminismos múltiples, oriundos de diversas organizaciones y articulaciones en la sociedad civil. Siguiendo esta línea de raciocinio, 
busqué entender de qué maneras los feminismos brasileños y latinoamericanos, en plural, brotaron de múltiples fuentes, fluyeron por múltiples corrientes.

Finalmente, un tercer momento en mis observaciones de campo sobre los campos se dio cuando tuve la oportunidad de inmersión, reciente e intensiva, en el campo feminista brasileño durante un sabático en 2013-14, y otro en 2019, con incursiones más breves a lo largo los 2010s, momento en que los feminismos brasileños y globales parecían "volver a las calles" en grandes protestas como las que sacudieron a todo el Brasil en $2013^{3}$. Llegué entonces a la conclusión de que el lenguaje de campos resultaba un tanto estático para caracterizar feminismos que ahora se movían bastante. Buscando conceptos más adecuados, me encontré con la noción de assemblage o ensamblaje, que me pareció más apta para captar las multiplicaciones y reconfiguraciones vertiginosas que han caracterizado a los feminismos de los últimos tiempos.

Al profundizar mis investigaciones sobre algunas vertientes feministas como los feminismos Afro-descendientes-en sí, ya siempre plurales-también reajusté mi gramática político-conceptual para enfatizar que el feminismo no se convirtió en, sino que siempre era ya un campo discursivo de acción, anclado en discursos compartidos, aunque constantemente disputados y reelaborados, en parámetros continuamente redibujados y reconfigurados, y en epistemes o "visiones de mundo"compartidas, aunque también siempre en pugna. En seguida elaboro la noción de campos discursivos de acción para luego contar algunos cuentos feministas que le den cuerpo empírico, y al final proponer una gramática complementaria fundamentada en la idea de assemblages o ensamblajes activistas.

\section{Teorizando los Campos Discursivos de Acción y los Ensamblajes Activistas}

Los campos discursivos de acción son mucho más que una mera aglomeración de lo que los sociólogos llaman organizaciones de movimiento social o social movement organizations (SMOs por su sigla en inglés). Abarcan una amplia gama de actoras y actores individuales y colectivos y de sitios culturales, sociales y políticos en escalas local, nacional y transnacional. En diferentes contextos, diversas actoras o redes de actoras que se relacionan en esos campos pueden ganar mayor o menor visibilidad política y cultural, y mayor o menor acceso a los micrófonos públicos y a las arenas de formulación e implementación de políticas públicas.

Los campos discursivos de acción se articulan formal e informalmente a través de redes reticuladas. Éstas no sólo vinculan a ONGs y colectivos que llevan el nombre feminista, sino que también interconectan a individuos y agrupaciones más o menos formalizadas que se identifican como feministas, situadas en diversos espacios y lugares en la sociedad civil, en la "sociedad no cívica"-que a menudo se articula políticamente en las calles y en el campo, y a la que acostumbro llamar el "Otro de la Sociedad Civil"-, en

\footnotetext{
${ }^{3}$ Para una muestra de la ya vasta literatura sobre las llamadas "jornadas de junho" de 2013, ver Dowbar y Swako 2013; Pinto 2017; Schwarz y Arantes 2013; Singer 2014; Saad-Filho 2014. Ese momento de movilización masiva es considerado por algunas como marcando el inicio de la "quarta ola" feminista. Al respecto, ver Perez y Ricoldi 2018.
} 
la sociedad política (partidos), en el Estado, en las instituciones intergubernamentales, en la academia, en las industrias culturales, en los medios tradicionales y alternativos, y así sucesivamente. Los componentes de estos campos se entrelazan a través de cruzamientos continuos de múltiples niveles y camadas, entre personas, prácticas e ideas $^{4}$.

Los campos discursivos de acción nunca son estables, mucho menos estáticos, sino que siempre están en movimiento. Por lo tanto, los límites de quién o qué es propia o legítimamente feminista tienen que ser impuestos y controlados por actoras que se establecen como hegemónicas dentro del campo en un determinado momento o contexto. Pero esos límites también son permanentemente desafiados y mudan en función de luchas políticas que involucran contestación, traducción, y reapropiación.

Los campos feministas, como ya sugerí, se articulan discursivamente a través de lenguajes, significados y visiones del mundo compartidas. Sin embargo, éstas son siempre impugnadas, contestadas. En ese sentido, los campos feministas son constituidos por enmarañados de interlocuciones.

Tales espacios constituyen formaciones políticas en sí mismas, donde la ciudadanía se construye y se practica, los derechos son imaginados y no solo demandados, las identidades y necesidades son forjadas, la subjetivación se promueve, y el poder y los principios se negocian y disputan. Por lo tanto, la contención y la contestación de significados $y$ del poder son elementos constitutivos de los campos discursivos de acción feministas. Como toda formación política, los campos discursivos de acción están siempre minados por desigualdades y por relaciones asimétricas de poder, y siempre están marcados por la disputa y muchas veces por la ruptura. Esto no debe necesariamente lamentarse, sino que debe ser entendido como un (casi siempre) saludable "publicitar" de las contradicciones y paradojas que son precisamente lo que hace que lo que llamamos movimientos se muevan.

Mis más recientes inmersiones en los campos de los feminismos en el Brasil me suscitaron una última realineación conceptual. Las dinámicas de los feminismos afrobrasileños, en particular, me llevaron a pensar sobre la política ontológica y sobre la configuración de campos feministas emergentes. Se trata de campos distintivos anclados en mundos diferentes, $y$, por lo tanto, fincados en entendimientos y miradas distintas que surgen desde esos diferentes mundos.

Los discursos y prácticas feministas actuales se multiplican a un ritmo acelerado y las personas que se consideran feministas están involucradas en un extenso y variado abanico de acciones. Por lo tanto, los feminismos de hoy en día no son sólo plurales, sino multi-situados e internamente hiper-heterogéneos. Podemos pensar en las practicas móviles de las feministas anarco-autonomistas y en las expresiones multitudinarias de protesta feminista de la actualidad como ejemplos por excelencia de esa heterogeneidad dinámica y multi-situada.

La disputa sobre los parámetros de lo auténticamente feministafue, a mi modo de ver, constitutiva de los campos feministas de finales del siglo XX. Hoy, indiscutiblemente, esos límites son tan difusos, tan mutables, se mueven tan rápidamente, que se vuelve

\footnotetext{
${ }^{4}$ Para un análisis empírico de esos cruzamientos en el Brasil reciente, ver Matos y Alvarez (2018).
} 
mucho más complicado disputarlos o contestarlos políticamente (jlo cual no impide que muchas lo hagamos!). Los múltiples espacios de activismo feminista se combinan y recombinan, chocan entre sí, rebotan, se remontan y se re-ensamblan unos con los otros, muchas veces armando relaciones dinámicas y contingentes a través de las cuales se transforman a sí mismos y a otras actoras en su entorno. El activismo feminista de hoy en día, por lo tanto, no es solo rizomático, sino más bien algo que se parece y se siente más como lo que algunos vienen teorizando como assemblages o ensamblajes (ver Escobar 2008; MacFarlane 2009; Müller 2015; Nial 2017).

Los ensamblajes activistas desestabilizan los parámetros (ya siempre controvertidos) de los campos feministas; reorganizan sus elementos discursivos (por ejemplo, hemos pasado de la "perspectiva de género" al patriarcado, la misoginia, el feminicidio) y reconstituyen sus prácticas políticas (hoy vemos el auge de los feminismos callejeros, los feminismos virtuales). Los feminismos en protesta, si se quiere, concatenan nuevas actoras y a veces, como veremos, pueden generar campos emergentes. Quiero proponer entonces que "assemblage thinking" 0 el pensamiento teórico sobre ensamblajes activistas (Conway, Osterweil y Thorbun 2018) puede ofrecernos un lenguaje conceptual útil para teorizar expresiones actuales, y como veremos, también históricas, del activismo feminista contemporáneo a nivel regional y global.

Ahora presento tres referentes temporales con el objetivo de ilustrar la heterogeneidad del campo feminista brasileño y sus reconfiguraciones vía ensamblajes activistas en distintos momentos, buscando resaltar una multiplicidad que a su vez pone a prueba una de las afirmaciones más comunes sobre cómo "se mueven" los feminismos, que sería en olas: un primer referente temporal es el momento considerado "fundacional" de los feminismos contemporáneos, un segundo es el que yo y otras hemos llamado de "oenegización" en los años noventa, y un último referente es el actual; en todos ellos hago énfasis en el caso del Brasil.

\section{El feminismo "en lo singular" siempre era ya un campo}

Un primer referente atañe a cómo el feminismo de los setenta y ochenta se construyó en lo singular, a pesar de que, como quiero sugerir, siempre era ya un campo discursivo de acción heterogéneo, plural. Éste sería el momento fundacional de la llamada "segunda ola" del feminismo en el Brasil y en el resto de América Latina. Como tal, existe una especie de "historia oficial," un mito de origen, consagrado en los relatos de activistas veteranas y en los escritos de algunas de sus primeras analistas, inclusive yo misma, quienes caracterizan aquel momento como uno en el que el feminismo, digamos así, se parecía más a lo que acostumbramos a pensar que sería un movimiento social "de verdad", como apuntan Ríos, Godoy y Guerrero en su libro Un Nuevo Silencio Feminista? en el caso de Chile (2003) ${ }^{5}$.

Las feministas fundadoras, según este mito, "se movían" bastante. Estaban firmemente ancladas en el campo más amplio de oposición a las dictaduras. De hecho,

\footnotetext{
5 Para historias diversas sobre los feminismos brasileños, ver Cardoso (2012); Carneiro (1999); Pinto (2003); Riberio (1995); Teles (2017).
} 
muchas provenían de la lucha clandestina. De acuerdo con este mito de origen, las feministas "de aquellos tiempos" por definición se organizaban en grupos autónomos que eran auto-sustentados, basados en trabajo voluntario. Regularmente protestaban en las calles por el fin de la subordinación de las mujeres, en contra de la dictadura militar, por la amnistía y los derechos humanos, y por el derecho a su cuerpo. La autonomía-en aquel entonces invocada principalmente en relación con los partidos clandestinos y las organizaciones revolucionarias de la izquierda-se volvió una especie de "palabra mágica" usada para distinguir entre las feministas auténticas y "otras" mujeres militantes (Schumahery Vargas 1993).

Dicho feminismo fundacional se construyó en lo singular en relación con lo que podríamos llamar su "exterior constitutivo." Ellas serían las feministas, en contraste con la izquierda revolucionaria que relegaba la "cuestión de la mujer" al plano de "una contradicción secundaria;"en contraste con otras mujeres que militaban en la oposición, a quienes las "feministas autónomas" peyorativamente designaban de "políticas" por priorizar, presumiblemente, la lucha general; en contacto muy cercano, pero también en contraste, con los cientos de grupos de mujeres populares que proliferaban por todo el Brasil, muchas veces ligados a la iglesia católica; y en distinción a la caricatura, promovida por los medios dominantes al igual que por la izquierda ortodoxa, de la mujer burguesa que odiaba a los hombres, esto es, la feminista imperialista del Norte.

Las oposiciones binarias "lucha general/activismo político", por un lado, y "lucha específica/activismo autónomo", por el otro, se convirtieron en una especie de discurso articulatorio, en elemento central dentro de una gramática política compartida que entretejía al incipiente campo feminista-tanto a través de la contestación y la disputa como de la colaboración ocasional. Esas dicotomías se volvieron objeto de disputas continuas y muchas veces amargas, convirtiéndose así también en un conflicto constitutivo del campo feminista brasileño de los años setenta y comienzo de los ochenta.

Como la reciente historiografía sobre el período nos viene revelando, las activistas etiquetadas de militantes o políticas - términos que abarcaban a casi todas aquellas que continuaron militando en los diversos movimientos populares, en redes de defensa de los derechos humanos, en el movimiento negro, en el movimiento gay, en los sindicatos, y en los diversos los partidos de izquierda - fueron excluidas del incipiente movimiento feminista por definición ${ }^{7}$. Sin embargo, muchas mujeres que no renunciaron uniformemente a tales tipos de militancia siguieron identificándose con algunas ideas (siempre reapropiadas y traducidas) feministas $y$, por lo tanto, en el presente encuadramiento, formaban parte de lo que estoy llamando campo discursivo de acciónincluso cuando, por ejemplo, muchas veces se les negaba la pertenencia plena a un

\footnotetext{
6 Ver especialmente Pedro y Wolff 2010; Pedro, Wolff y Veiga 2011; Rago 2009.

7 En mi primer libro, yo también excluí de mi análisis, por definición, a muchas actoras del campo feminista de los ochenta: "Women's movements pursue women's gender interests [according to Molyneux 1985, 'those that women (or men, for that matter, may develop by virtue of their social positioning through gender atributes)]. Excluded from this definition, then, are State-linked mass organizations for women, women'sbranches of political parties, trade unions and other organizations of civil society that are not primarily organized to advance women's gender-specific concerns" (1990, 23, fn 9).
} 
feminismo construido "en lo singular" por aquellas que insistían en que la autonomía absoluta era una dimensión obligatoria de la práctica auténticamente feminista.

$Y$ ese conflicto, esa lucha interpretativa se jugó a nivel local, nacional y, ya en esos tiempos, a escala transnacional en los Encuentros Feministas Latinoamericanos y del Caribe, que comenzaron a realizarse cada dos o tres años a partir de 1981. Como sabemos, durante los primeros Encuentros, se dieron batallas épicas y enfrentamientos acerbos entre "feministas" y "políticas". También se desencadenaron conflictos estridentes en esos espacios transnacionales acerca de si las mujeres de los movimientos populares, las negras y otras "otras" que se identificaban con algunos aspectos del feminismo podrían ser consideradas feministas "verdaderas". La combinación "lucha específicamilitancia autónoma" a final logró la hegemonía en esa disputa constitutiva-talvez justamente porque la idea de que lo personal, lo íntimo era políticamente importante también resonó para esas "otras," pero talvez también debido al capital social y cultural y los privilegios de raza y clase que muchas de las que adhirieron a la posición autonomista poseían.

A pesar de la estrecha delimitación del "movimiento" feminista producida por esta hegemonía discursiva, no pocas entre las "otras" de este feminismo hegemónico asumieron sus propios caminos feministas, pasando así a formar parte, aunque aún fuera de manera marginal, de lo que yo teorizo como el campo discursivo de acción feminista. Algunas consideraban que la llamada "lucha específica"-la supuesta línea divisoria entre el feminismo hegemónico y su exterior constitutivo-estaba profundamente marcada por la clase social, por la heteronormatividad, y por una blancura/blanquedad no identificada 0 implícita, por una posición racial presuntamente neutra y no-reconocida que constituía su fondo silenciado (Maia 2012) ${ }^{8}$. Como sustentaba la intelectual-activista feminista afrobrasileña Lélia González, "para ellas la mujer negra tenía que ser antes que nada una feminista de cuatro costados, preocupada por las cuestiones que ellas priorizaban..." (González 1991 en Schumaher 2018, 35).

Para finales de la década de los setenta, González y algunas otras activistas negras organizadas dentro del movimiento afrobrasileño entablaron sus propias discusiones sobre la relevancia del feminismo y su relación con el racismo y el antiracismo. A principios de la década de los ochenta, ya se consolidaban grupos de mujeres negras que se declaraban "autónomas" del movimiento feminista "blanco", así como del movimiento negro "mixto" (Lemos 1997 en Santos 2009, 277) ${ }^{9}$. Mujeres afrobrasileñas y otras activistas que continuaron militando en sindicatos, movimientos populares y partidos de la izquierda inventaron sus propios feminismos, a la vez que adaptaron, tradujeron y resignificaron los discursos feministas denominados "fundacionales".

Desde comienzos de la llamada segunda ola, entonces, el feminismo siempre era ya un campo discursivo de acción. "La política que produce y sostiene una versión de la historia como más correcta o verdadera que otra," en este caso, la historia oficial sobre los

\footnotetext{
${ }^{8}$ Sobre 'branquitude’ en el Brasil, ver también Bento 2002; Piza 2000; Slovik 2009.

9 Para historias diversas sobre los feminismos afrobrasileños, también fundacionales, ver Caldwell (2007); Cardoso (2012; 2016); Carneiro (1995); Moreira (2011); Rodrigues y Prado (2010); Ribeiro (1995; 2006); y Santos (2009).
} 
orígenes del feminismo brasileño, la política que sustenta una versión del feminismo en los setenta y ochenta como aúnica versión, como diría Clare Hemmings, empieza a quedar más clara cuando una realinea su gramática política y conceptual para "contar los cuentos feministas de otra manera". Es más, resaltar la producción siempre múltiple y relacional de los feminismos también nos debería llevar a cuestionar qué es "fundacional," para quién y cuándo. Los debates constitutivos entre diversas corrientes activistas del movimiento de mujeres negras-disputas discursivas sobre si las mujeres negras deberían dedicarse principalmente al movimiento negro, a la lucha de clases, al feminismo, o a construir un movimiento de mujeres negras autónomo en relación con esas otras luchas (Carneiro 1999) - se realizaron principalmente en los ochenta, por ejemplo, y no por eso dejan de ser "fundacionales" para el campo feminista brasileño en general ${ }^{10}$.

\section{Feminismos plurales más allá de la institucionalización y la oenegización}

Paso ahora a un segundo referente temporal, el de los años noventa, el cual analizaré mucho más sucintamente aquí, más que nada para tratar nuevamente de señalar la heterogeneidad de otro momento en que se ha pensado al feminismo de forma homogénea y, en este caso, binaria. Éste sería el momento en el que la historia oficial del feminismo proclama que "el movimiento" se "institucionalizó"11 — caracterizando lo que algunas analistas han llamado de "tercera ola feminista" (Matos 2014; Schumaher 2018). En efecto, parecía que, por un lado el feminismo ya no se movía mucho (Barrig 1998); por el otro, muchas feministas se reposicionaron "más allá de la sociedad civil", adentrándose en las más variadas instituciones dominantes, como indiqué al inicio de este ensayo (Alvarez 2014b, 2001). Diagnósticos de que "el movimiento" estaría desmovilizado, despolitizado, cooptado y hasta moribundo, cuando no completamente acabado, abundaban en las filas feministas, tanto activistas como académicas ${ }^{12}$.

Las ONGs jugaron un papel indiscutiblemente hegemónico en los campos discursivos de acción feminista de los noventa. Ya fueran vistas como la Coca Cola del desierto, o como siervas o concubinas del patriarcado neoliberal global, las ONGs figuraron entre las actoras más visibles (y más controvertidas) en los campos feministas brasileño, latinoamericano y globalen aquellos años (Alvarez 1999; Lebon 1998; Thayer 2010). Con sus sedes permanentes, presupuestos abundantes, departamentos especializados y personal remunerado, las ONGs se convirtieron en lo que podríamos llamar verdaderos pilares, nódulos articuladores por excelencia, de los ahora aún más descentrados campos feministas. Produciendo y diseminando conocimientos y discursos, a la vez que ejecutaban los más diversos proyectos, las ONGs y las redes temáticas especializadas que las vinculaban ayudaron a entrelazar también a otras actoras

\footnotetext{
10 Sobre "fundaciones sin orígenes," ver Bernal (2017).

11 Ver Alvarez et al. (2003); Barrig (1998; 2001a and 2001b); Olea Mauleón (1998); Vargas (1998).

12 Para ejemplos diversos de como la "institucionalización del movimiento" en la region se contó, ver Jaquette y Wolchik, 1998; Gaviola, Largo y Palestro, 1994; Richard, 2001; Vargas, 2000. Para el caso del Brasil, ver especialmente Castro, 2001.
} 
feministas ahora ampliamente esparcidas por el tejido social, a veces ayudando a articularlas organizativa y discursivamente (Alvarez 2009; Murdock 2008).

Sin embargo, si algunas de las ONGs más transnacionalizadas, profesionalizadas y especializadas conformaron un nuevo núcleo hegemónico del feminismo en aquel momento, muchas otras circulaban, aunque invisibilizadas, por ese campo, transformándolo en el camino. Por ejemplo, en el propio feminismo chileno, entonces considerado por muchas analistas como el más "institucionalizado" y "oenegeizado" de la región latinoamericana, surge, como sabemos, el autodenominado movimiento feminista autónomo-con críticas feroces a las "institucionalizadas" que ellas veían como su exterior constitutivo. Pero, además, en Chile surgieron más de 30 colectivos organizados informal y horizontalmente precisamente durante el pico de la llamada institucionalización del feminismo-como lo muestran Ríos, Godoy y Guerrero (2003).

En el Brasil, a pesar de ser muchas veces efímeros y no siempre visibles políticamente, cuando no deliberadamente reprimidos en el contexto neoliberal, colectivos y otras agrupaciones feministas menos estructuradas continuaron organizándose durante el auge de las ONG-por ejemplo, los primeros grupos de Riot Girrls y colectivos feministas de la escena anarco-punk (Marques 2013; Do Carmo 2018), al igual que otros grupos organizados dentro de movimientos de la juventud, como el hip-hop y el movimiento estudiantil dentro de las universidades, dentro de los sindicatos urbanos y rurales brasileños y La Vía Campesina, y dentro de diversos movimientos étnico-raciales (Barbosa, 2013; Godinho, 1998; Magrini y Lago, 2013; Silva, 2008).

Además, esa heterogeneidad también se produjo precisamente desde lo institucional a través de procesos regionales como por ejemplo los ya mencionados Encuentros y el proceso de Beijing. Las más de mil participantes en el Foro de ONGs de América Latina y el Caribe, celebrado juntamente con el PrepCom regional de la CEPAL, realizado en Mar del Plata, Argentina, en septiembre de 1994, parecían encarnar, a nivel regional, la creciente heterogeneidad de actoras y practicas feministas que yo había presenciado en el Brasil. Entre ellas se encontraban las autodenominadas "feministas peronistas" y activistas partidarias de todas las tendencias ideológicas que proclamaban haber abrazado aspectos centrales de (al menos) una agenda liberal feminista de "igualdad de mujeres;" activistas negras de Perú, Bolivia, Colombia, Nicaragua, Brasil, República Dominicana y Uruguay que declaraban lealtad tanto a los movimientos negros como a los feminismos; prominentes académicas feministas que ahora servían como consultoras para gobiernos, fundaciones y agencias sobre la mejor manera de promover la "igualdad de género;" participantes de partidos clandestinos de los años sesenta y setenta, quienes a principios de los años ochenta habían fundado colectivos feministas y ahora eran profesionales en ONGs nacionales e internacionales de mujeres, medio ambiente, derechos humanos o desarrollo; algunas "madres fundadoras" de la segunda ola de feminismos latinoamericanos que trabajaban ahora para UNIFEM (Fondo de Desarrollo de las Naciones Unidas para la Mujer) y otras agencias de la ONU; líderes de movimientos de base del Perú, Brasil, Nicaragua y México que se proclamaban"feministas populares;" directoras y personal de mecanismos gubernamentales de la mujer, algunas de las cuales tenían extensas trayectorias anteriores como feministas autónomas; y teólogas católicas y religiosas y laicas en Católicas por el Derecho a Decidir, la afiliada 
latinoamericana de Catholics for Free Choice, con filiales en Perú, Colombia, Uruguay, Bolivia, Argentina, Brasil, México y Chile, que desafiaban el anti-feminismo dogmático de la Iglesia.

Ya hacia mediados de la década de los noventa, entonces, el límite, siempre borroso, demarcando lo que constituirían prácticas feministas y no feministas evidentemente estaba aún más en disputa, desafiando directamente el mito de la unidad originaria de "el" movimiento. Muchas mujeres que se auto-identificaban como feministas ahora habían ingresado a instituciones gubernamentales, habían transformado grupos informales feministas o fundado ONGs profesionalizadas, temáticamente especializadas y enfocadas en políticas públicas, participaban en secciones de mujeres de los partidos políticos convencionales y no sólo en los revolucionarios, y practicaban sus feminismos dentro de otras instituciones sociales, religiosas o académicas, o en organizaciones y movimientos sociales "mixtos" de la sociedad civil que incluían a mujeres y hombres, feministas y no feministas.

\section{Feminismos en Protesta y Reflexiones sobre Assemblages o Ensamblajes Activistas}

La multiplicidad y conflictividad inherente a los campos discursivos de acción se han manifestado de forma clara y, a veces, verdaderamente espectacular en esta última década, momento en el cual la protesta social ha sobresalido tanto en los enfoques académicos como los políticos sobre el campo feminista ${ }^{13}$. Pasando a la parte final de este ensayo, contaré tres cuentos sobre los feminismos actuales, con el fin también de elaborar, analíticamente, la noción de assemblages o ensamblajes activistas: dos más breves sobre la Marcha das Vadias (la versión brasileña del fenómeno global "SlutWalk" o Marcha de las Putas, como se ha llamado en lugares como Ecuador y Perú), y la "escena" o el "rolê" anarco-feminista a través de dos "festivales" feministas; y un tercero, un poco más detallado, sobre modalidades de organización feminista innovadoras entre las mujeres afro-brasileñas, a través de la historia del proceso que precedió y sucedió a la Marcha de las Mujeres Negras contra el Racismo y la Violencia y por el Buen Vivir, realizada en Brasilia en noviembre de 2015.

La Marcha das Vadias ha movilizado a decenas de miles de mujeres, feministas trans y no-binarias, y hombres solidarios homosexuales y heterosexuales, en innumerables ciudades brasileñas desde su primera edición en el $2011^{14}$. Literalmente encarnando sus feminismos al proclamar y diseñar consignas transgresoras, noconformistas, cuir, antirracistas, trans-inclusivas, y pro-justicia social en sus cuerpos, su

13 Para una caracterización de este momento de protesta a nivel global, ver especialmente McGlazer (2018). Para el Brasil, ver Buarque de Holanda (2018); Matos (2014); Alvarez (2014b).

${ }^{14}$ Para algunas otras historias sobre las Vadias, ver Gomes y Sorj, 2014; Hermida, 2018; Name y Zanetti, 2013; y Saads y Libia, 2019. 
desafío público y rebelde a las normas culturales sobre géneros y sexualidades impertinentemente promueve una intervención cultural radical (Gomes 2018; Gutto 2019). ¿Por qué el término "Vadias"? Una respuesta, de las Vadias de la ciudad de São Carlos, en el interior del estado de São Paulo, es la siguiente:

"Nos apropiamos de este término [vadia] porque nos damos cuenta de que es una palabra utilizada para dirigirse a las mujeres cuando demostramos cualquier tipo de actitud de libertad, especialmente libertad sexual. Si ser libre significa ser una puta, entonces todas somos putas. Vivimos en una sociedad que está escandalizada por las palabras fuertes, pero no por la violencia [contra las mujeres]" (citado en Ferreira 2012, 40).

En un llamado de preparación para la Marcha de 2018 en Pernambuco, la página de Facebook de las Vadias proclamaba:

\#Vadias Invita a una conversación sobre la "Importancia de la resignificación de términos en los movimientos sociales". Hablaremos sobre las vadias, ese nombre tan polémico, su importancia y las problematizaciones en torno a él. . . Es una práctica ya reconocida como "Resignificar para derrotar". Vaciar la palabra del sentido que el opresor le ha dado para resignificarla de forma transgresora. Para hablar de las gays, de las bi, de las trans y las sapatonas todas organizadas para hacer revolución. Para hablar de las gordas, porque gorda no es insulto. Para hablar sobre el "100\% Negro" entre otras formas de afirmar la negritud con orgullo. (Colectiva de las Vadías de Pernambuco, en Hermida 2018, 151).

La Marcha das Vadias ha realizado intervenciones culturales que, junto con la efusiva escena o "rolê" anarco-feminista, la multitud feminista del hip hop, las Blogueras Feministas, las Blogueras Negras, las "minas do rock" (la escena roquera de chicas), y muchas otras expresiones lúdico-culturales y políticas más visibles en los últimos años señalan la creciente "popularización del feminismo" entre nuevas generaciones de activistas.

Muchas de las diversas feministas de los años 2010 declaran que quieren construir un "movimiento feminista que vuelva a las calles" (Name y Zanetti 2013, 15), y ven el feminismo desde una perspectiva irreverente: quieren "volver a hacer del feminismo una amenaza real," como lo expresó una de las Vadias de Florianópolis en una entrevista en 2014, resumiendo vívidamente un sentimiento que prevalece entre nuevas generaciones feministas ${ }^{15}$. Al igual que la Marcha das Vadias, una amplia gama de otras expresiones de feminismos hiper-heterogéneos, provenientes de múltiples flujos, que frecuentemente (y creo, erróneamente) se agrupan bajo la categoría homogenizante de "feminismos jóvenes", estan empeñadas en socavar formaciones dominantes del poder a través de intervenciones lúdico-político-culturales innovadoras.

${ }^{15}$ Entrevista colectiva con la Coletiva Vadias do Desterro, Florianópolis, 13 de Noviembre de 2013. 
Otra modalidad de organización feminista reciente en el Brasil es el "festival", un formato que, como un grupo de activistas que estaba organizando el primer "Anti Fest Suspirin Feminista" en Belo Horizonte para abril de 2014 me explicó, es más fluido, menos estructurado que los Encuentros feministas de antaño: "es algo mucho menos académico, una especie de hazlo-tú-misma, es contacto con las calles, reunirse y hacerlo por nosotras mismas". Es "un aliento feminista de aire fresco [un suspirín o suspirito] en medio de la violencia machista y el desorden de la vida... Es un intento de practicar juntas formas feministas de relacionarse entre sí y de construir zonas autónomas de resistencia feminista" (Martello, 2015: 75). Para tener un sabor de su agenda cultural y política, basta decir que este evento anarco-autonomista incluyó "cocina vegana, espectáculos, debates sobre transfeminismo, activismo feminista contra el complejo penitenciario industrial, discusiones sobre el cabello afro y binarismos, lanzamientos de fanzines, talleres sobre autodefensa, gordofobia y cuerpas, FTM, juguetes sexuales hazlo-tú-misma y nalgadas eróticas, entre otros temas"(Ibid.).

El AntiFest se inspiró parcialmente en un festival similar, celebrado anualmente en Salvador, Bahía, entre 2010 y 2013: el Festival Vulva La Vida, cuya consigna en su tercera edición era "orgullosamente feministas, necesariamente inconvenientes". La convocatoria para la reunión, publicada a través de redes sociales y en su sitio web, describía al evento de la siguiente manera:

"Es un festival contracultural feminista: a través de la ética de hazlo-tú-misma, creemos que el cambio no depende de la iniciativa de los partidos políticos y las instituciones; debemos practicarlo a diario, desarrollando nuevos valores para las relaciones atrapadas en la vida cotidiana. Esto implica repensar nuestros hábitos más "íntimos," hacer la revolución tanto en la calle como en la cama. ¡La política también es divertida!" (citado en Gonçalves et al. 2013, 19).

Algunas feministas afrobrasileñas critican la Marcha das Vadias y algunas otras expresiones feministas recientes, como los Festivales y la escena anarca-feminista, que entienden como aún mayoritariamente blancas y de clase media, por su dificultad para "tratar la especificidad de las mujeres negras" y exigir que "el antirracismo deje de ser una verborrea fácil y se convierta en una práctica cotidiana abrazada por todos, mujeres y hombres" (Hermida 2014, 13). Como lo dijo una feminista negra, organizadora de las Vadias en Salvador, "el racismo nos etiqueta como putas y vadias desde el día en que nacimos debido a la raza. El racismo histórico nos atrapó y aprisionó dentro de nuestra propia sexualidad y eso es algo que, durante años, las luchas de las mujeres negras han estado trabajando para deconstruir" (lbid., 14).

La Marcha das Mulheres Negras contra o Racismo, a Violência e pelo Bem Viver emprendió esa deconstrucción del racismo sexuado de una manera sin precedentes, enseñando un expresivo y dinámico assemblage o ensamblaje activista y así lanzando un proceso organizativo extenso, intenso einnovador que, quiero sugerir, reconfiguró tanto a los movimientos de mujeres negras como al campo feminista más amplio, facilitando la rearticulación de un campo feminista afrobrasileño emergente, internamente heterogéneo-al igual que todos los campos discursivos de acción. Realizada en Brasilia 
el 18 de noviembre de 2015, la Marcha, en sí, que de acuerdo con informes variados reunió entre 20,000 y 50,000 personas de todo Brasil, fue la culminación de un proceso de movilización a nivel nacional sin precedentes que duró varios años (comenzando a fines de 2011, el Año Internacional de las Naciones Unidas para los afrodescendientes) y abarcó todas las regiones del país.

Considerada como un importante punto de inflexión, un verdadero hito en el activismo de mujeres afrobrasileñas, la Marcha involucró a todos los sectores concebibles de mujeres afrodescendientes organizadas y a muchos activistas del movimiento negro brasileño de ambos sexos. Aunque muchas activistas y organizaciones negras brasileñas ya formaban parte de redes nacionales como la Articulação de Organizações de Mulheres Negras, el Foro de Mujeres Negras, la Federação de Trabalhadoras Domésticas, el Seminario Lésbico Negro Nacional, y el Frente Nacional de Mulheres no Hip Hop, la Marcha buscó llegar a todas las mujeres negras involucradas en cualquier tipo de esfuerzo de cambio social en una excepcionalmente amplia gama de espacios y lugares, urbanos y rurales, gubernamentales, religiosos, sindicales, académicos y artísticos, y muchos más.

Como lo captura su eslogan "Vem Marchar com a Gente," las articuladoras de la Marcha a lo largo de Brasil trabajaron especialmente para atraer a mujeres "que nunca habían asistido a una reunión del feminismo hegemónico" para participar en "la construcción de la Marcha," comenzando desde dondequiera que estuvieran situadas, sin importar dónde trabajaban ni dónde practicaban su activismo, encualquierforma que se estuvieran organizando para promover la justicia racial, de género, sexual, y social.

El éxito de la Marcha en llegar a decenas de miles de mujeres negras y sus aliadas y aliados en todo el Brasil, en toda su heterogeneidad, implicó estrategias de organización y difusión excepcionalmente creativas, incluyendo festivales de artes, talleres de envoltura de turbantes y trenzado de pelo, sambas, saraus (arte alternativo/cultural/performance/eventos), xirês (danzas usadas para convocar Orixás u Orishas, deidades religiosas africanas), blogs, páginas de Facebook, chats, poesía hablada y eventos de hip hop, junto con un elenco más estándar de decenas de conferencias, debates, manifestaciones y reuniones sindicales y de partidos políticos, reuniones de trabajadoras domésticas y sexuales, etc. Se crearon Comités Impulsores estatales y municipales autónomos en decenas de ciudades y pueblos, al igual que un comité nacional de coordinación. La mayoría incluía representantes de diversos grupos y redes de mujeres afrobrasileñas, así como de organizaciones negras mixtas, sindicatos y otras redes, quienes, de acuerdo con los estatutos de Marcha, tenían que ser representados por miembros mujeres.

Algunos lugares donde el activismo feminista negro contemporáneo se remonta a la década de los setenta, como Rio de Janeiro, celebraron sus propias "pre-marchas" con manifestaciones muy visibles que atrajeron a miles de participantes. En el proceso que precedió a la Marcha de 2015, activistas negras jóvenes del estado sureño de Santa Catarina, un estado de mayoría euro-descendiente, organizaron un evento de moda y música "Afro-Divas" en Florianópolis y un "I Encontro de Arte e Cultura Negra: Mulher Negra em Foco" en la ciudad de Joinville, donde predominó la emigración alemana. Activistas feministas negras de Salvador, una ciudad de mayoría afrodescendiente en el 
estado de Bahia, quienes actuaron en la coordinación nacional de la Marcha, transformaron el JulhodasPretas, una serie de eventos y celebraciones inauguradaa nivel local a principios de la década de 2010, en un fenómeno nacional, que llegó a pueblos minúsculos y grandes metrópolis por igual, marcando la conmemoración del Día Internacional de las Mujeres Afrolatinoamericanas y del Caribe (25 de julio). La Marcha da Mulheres Negras y el Julho das Pretas (denominado julho negro en algunos estados) se siguen organizando y celebrando en lugares tan diversos como São Paulo, Brasilia, Goias, Rio de Janeiro, Belo Horizonte y muchas ciudades menores también.

La participación significativa, si no mayoritaria, de mujeres activistas negras del norte y noreste-las regiones más negras/más oscuras y (no por casualidad) más pobres de Brasil-fue una dimensión particularmente notable de la Marcha Nacional das Mulheres Negras. Históricamente, los estados más ricos y más euro-descendientes del sur y del sudeste, con sus ONGs más institucionalizadas y mejor dotadas de recursos, a menudo han eclipsado a sus contrapartes en el norte y el noreste. Pero en este caso los esfuerzos organizativos extraordinarios de Odara-Instituto da Mulher Negra (Instituto Odara de Mujeres Negras) y la Red de Mujeres Negras del Norte y Noreste que éste ayudó a fundar en 2013 lograron incorporar a cientos de mujeres populares, rurales y urbanas, al proceso de la Marcha. Su participación hizo que la pobreza, las desigualdades regionales y el desarrollo alternativo fueran elementos centrales de la agenda de la Marcha y se reflejaran también en la inclusión de la noción del"Buen Vivir" en su propio nombre. A las feministas socioambientalistas negras de la región norte de Brasil que trabajan regularmente en forma transnacional con mujeres de otros países de la Amazonía se les atribuye el hecho de llevar la idea del Buen Vivir al proceso organizativo de la Marcha.

La noción del Buen Vivir, como sabemos, evoca un discurso decolonial, hoy muy resonante en círculos activistas y académicos en la región andina y en otras partes de América Latina, un discurso que también viene ganando adeptas entre teóricas-activistas en el Brasil (Costa 2014), especialmente entre mujeres negras y mujeres indígenas (Cardoso 2012, 2016). Una de las principales articuladoras del proceso nacional de la Marcha, la veterana feminista bahiana y coordinadora de Odara, Valdecir Nascimento, me explicó que las mujeres negras "le dieron al término [Buen Vivir] [su] (nuestro) propio significado, señalando la necesidad de un nuevo pacto de civilización."'16

Para mí, esta idea de un pacto civilizatorio nuevo o alternativo sugiere la articulación de una política ontológica, una visión de mundo distintiva. Tener diferentes visiones de mundo implica no solo diferencias culturales o perspectivas distintivas sobre un mismo mundo (es decir, diferentes epistemologías) sino también diferencias ontológicas, percepciones desde o a partir de otros mundos, como lo muestra la insistencia en que la raza y el anti-racismo tienen que ser principios regidores de la acción feminista. Esa onto-epistemología distintiva, a su vez, señala la reconfiguración de un campo discursivo de acción emergente.

En las corrientes de pensamiento sobre assemblage, emergence o emergencia "sucede cuando las acciones de múltiples agentes que interactúan dinámicamente y

${ }^{16}$ Entrevista colectiva con activistas feministas negras, Salvador, BA, 11 de mayo de 2014. 
siguen reglas locales, en lugar de comandos descendentes, resultan en algún tipo de macroconducta o estructura visible" (Escobar 2008, Kindle Locations 5287- 5290). "La Emergencia se refiere a la existencia o formación de comportamientos colectivos: lo quelas partes de un sistema hacen juntas y que no harían solas"17. Por lo tanto, los assemblages o ensamblajes son productivos. Pueden producir nuevas organizaciones, nuevos comportamientos, nuevas expresiones, nuevos actores y nuevas realidades (Müller 2015, 28-29).Así, los ensamblajes activistas pueden dinamizar y desestabilizar los parámetros (ya siempre controvertidos) de los campos feministas; suelen reorganizar los elementos discursivos y las prácticas políticas de esos campos, agregan nuevas o reagregan viejas actoras ya veces generan campos emergentes.

La Marcha de las Mujeres Negras de 2015 pusode relieve las corrientes heterogéneas y los discursos distintivos que constituyen el campo feminista afrobrasileñoactual. Las trabajadoras sexuales negras se unieron a las mães de santo (sacerdotas de cultos afrobrasileños) que marcharon junto a feministas afrodescendientes lesbianas y trans que se besaron y abrazaron con teóricas y novelistas feministas negras y con congresistas y dirigentes sindicales negras. El evento también facilitó una convergencia momentánea y contingente, aunque no necesariamente alianzas duraderas, entre activismos feministas negros y otras corrientes feministas brasileñas como algunas anarcas, feministas blancas "históricas," ecologistas y Vadias.

Por lo tanto, analizar el proceso de la Marcha, al igual que otras expresiones de feminismos en protesta que hoy se despliegan en Chile, Brasil, y en toda la región y el mundo, me llevó a considerar que "pensar en assemglage" puede ser una manera útil de apreciar y teorizar los feminismos actuales (Conway, Osterweil y Thorburn 2018). ¿Por qué? Porque procesos locales se concatenaron y así remontaron y reordenaron los campos de activismo de mujeres afrobrasileñas y el campo feminista más amplio a su entorno. Ese campo, como me sugirió la ex ministra y activista feminista negra Luiza Bairros, en entrevista concedida en 2011 (Bairros y Alvarez 2016), era ya internamente bastante heterogéneo al inicio de la presente década. Entre sus varias vertientes encontrábamos a las domésticas, las quilombolas (mujeres de antiguos territorios de esclavos o de posesión histórica de comunidades negras), las lesbianas, las mujeres de comunidades religiosas africanas tradicionales y las jóvenes / hip-hoppers / grafiteras/ bgirls [breakdancegirls] / capoeiristas, entre otras.

Las trabajadoras del sexo, las hip-hoppereras negras y las trabajadoras domésticas afrodescendientes que se reunieron para la Marcha no necesariamente se relacionan de forma continua, virtual o "real". Sin embargo, hoy se combinan y recombinan, se ensamblan y se vuelven a reunir en diversos foros, como aquellos espacios activistas emergentes que se conformaron,a través del proceso mismo de la Marcha-por ejemplo, las innumerables colectivas que surgieron y se rearticularon continuamente desde el comienzo del proceso preparativo de la Marcha, en actividades vinculadas al Julho das Pretas, y en las varias Marchas locales, como ya mencioné. Durante el Foro Social Mundial, realizado en Salvador, Bahia, en marzo de 2018, muchas

17 En New EnglandComplexSystemsInstitute, https://necsi.edu/emergence, consultado el 17 de abril de 2017. 
de esas diversas expresiones del campo feminista afrobrasileño emergente, por ejemplo, participaron en un "Fórum Permanente de Mulheres Negras", organizado por varias entidades que impulsaron la Marcha Nacional de 2015. Ese Fórum lanzó un nuevo proceso de movilización nacional que a su vez promovió actividades en decenas de ciudades en preparación para el III Encuentro Nacional de Mujeres Negras. Este encuentro conmemoró treinta años de activismo feminista negro, reuniendo a más de mil delegadas seleccionadas en asambleas municipales y estadualesa lo largo y ancho del país en diciembre de 2018, y detonando nuevos procesos organizativos-como las redes de mujeres negras creadas recientemente en varias ciudades como Rio de Janeiro.

Muchas otras expresiones contemporáneas de los feminismos en protesta, las que algunas analistas han proclamado ser parte de una "cuarta ola" feminista (Matos 2014; Perez y Ricoldi 2018), como los paros/huelgas de mujeres del 8M, las manifestaciones multitudinarias de $\mathrm{Ni}$ Una Menos, la llamada Primavera Feminista y las colectivas feministas que surgen con las recientes ocupaciones de las escuelas secundarias en el Brasil, las movilizaciones masivas del \#EleNão contra la candidatura de Bolsonaro, y el llamado "tsunami feminista" chileno, también recopilan y reordenan los campos discursivos de acción feministas, desestabilizando sus parámetros de forma que los mismos resultan cada vez más difíciles de delinear políticamente (Buarque de Holanda 2018; McGlazer 2018).

El concepto de agenciamento/ensamblaje, como señala el geógrafo Colin Mac Farlane, "apunta... a la dispersión y la transformación" (2009, p. 566). La noción "enfatiza la reunión, la coherencia y la dispersión", llamando la atención al trabajo de "ensamblar y reensamblar prácticas socio-materiales que son difusas, enredadas y contingentes". Redirecciona también nuestra mirada analítica y política hacia la "espacialidad y la temporalidad: hacia los elementos que se juntan en una coyuntura particular sólo para después dispersarse o realinearse" (MacFarlane 2009, 562).

El assemblage es un modo de ordenar entidades heterogéneas para que funcionen juntas durante un tiempo determinado (Muller 2015, 28). Las partes pueden desenchufarse del ensamblaje y luego unirse a una compilación diferente. Assemblage representa una lógica alternativa a la lógica de la unidad. Una unidad sería un todo cuyas partes trabajan juntas como los órganos del cuerpo humano, las unidades no permiten la posible emancipación y recombinación de sus partes sin destruirse en el proceso (Nail 2017, 22-23).El valor analítico de la idea de assemblage, entonces, es que representa una forma de subrayar las diferentes cosas que podrían ensamblarse, montarse, para permitir cursos particulares de pensamiento o acción (Clarke 2015, p. 49).

\section{A modo de conclusión}

Concluyo con tres lecciones analíticas sugeridas por las varias historias relatadas aquí.Una primera lección se refiere a la noción de olas feministas. La idea de olas, como ya ha sido sugerido por otras expositoras (Hewitt 2010), muchas veces termina encubriendo bastante más de lo que aclara. Al tapar la diversidad inherente de los campos discursivos de acción feministas bajo una sola camada homogeneizadora, casi 
siempre esconde la heterogeneidad de expresiones feministas que está por detrás ${ }^{18}$. Además, como propone Patricia Brito, una feminista brasileña de la generación política actual, "en vez de pensar que un determinado feminismo supera a otro, como supone la idea de olas, podemos pensar que diferentes experiencias feministas conviven, convergiendo en la acción cotidiana y en la construcción de las manifestaciones" (2017, p.18-19).

Es crucial que reconozcamos la presencia simultánea de modalidades organizativas y discursos feministas típicamente asociados con diferentes olas: colectivas anarcapunks (cuarta ola) ya existían durante el apogeo de la oenegeización (tercera ola), como ya vimos; feministas negras y populares (tercera o cuarta ola?) ya hacían parte del movimiento supuestamente blanco y de clase media de los años setenta (segunda ola); las ONGs de advocacy y núcleos de estudios de género y los feminismos sindicales hoy coexisten en medio de los feminismos en protesta (la cuarta ola). Aunque concordaría con que lo digital y la fluidez, por ejemplo, constituyen dimensiones importantes de muchos feminismos hoy en día, como lo resaltan Perez y Ricoldi (2018), también se despliegan feminismos sindicales, populares, indígenas y otros-como la Marcha das Margaridas, que desde 2004 moviliza a decenas de miles de mujeres trabajadoras rurales, "das águas e das florestas"-que se organizan de forma más "convencional" $y$, muchas veces, incluso jerárquica, con base en partidos de izquierda, sindicatos y otras organizaciones de clasey/o étnicas que no "fluyen" de la misma manera.

Una segunda lección tiene que ver con la importancia de "contar las historias feministas de manera diferente", telling feminist stories otherwise. En lugar de intentar diagnosticar los flujos y reflujos, el éxito o el fracaso de los movimientos, el marco interpretativo y la gramática conceptual que he propuesto en este ensayo nos podrían permitir mapear y comprender mejor los feminismos mientras rebotan entre sí y se mueven. Nos permiten contar historias alternativas sobre sus trayectorias $y$ realineamientos cambiantes, en lugar de sus éxitos y fracasos, resaltando que en cualquier relato histórico siempre hay quien gana y pierde, sobresale y desaparece. Nos posibilitan intervenir en las historias feministas prevalecientes, como sugiere Hemmings, para "realinear su gramática política y permitir una visión diferente del pasado, presente y futuro feminista".

Y una tercera y última lección: los ensamblajes activistas suelen remodelar y resignificar las prácticas y discursos, así como los parámetros, de los campos discursivos de acción. Pero contra el impulso común de imaginar al momento actual como representando un nuevo o hasta "novísimo" momento del activismo feminista—una cuarta ola en la que prevalece la fluidez, lo digital, lo horizontal y la protesta-termino insistiendo que ni es el único ni el primero en que se vieron protestas feministas y feministas en protestas. Assemblage no es sinónimo de protesta. La óptica de assemblages nos serviría

\footnotetext{
18 Algunas reconocen las limitaciones analíticas de la noción de olas a la vez que continúan desplegándola. Declarando que la "cuarta ola" es "digital, interseccional, fluida y plural,", Perez y Ricoldi, por ejemplo, señalan que "el uso de la idea de olas sirve para organizar la realidad, apuntando tendencias del movimiento feminista, pero no debe ser limitadora de su análisis, desconsiderando la trayectoria, contradicciones, y diversidad del campo social $(2018,4)$.
} 
también para reorientar nuestras narrativas sobre el propio proceso de Beijing, por ejemplo, que podría ser pensado como un ensamblaje activista que dinamizó, reensambló, y desestabilizó los parámetros de los campos feministas de los setentas y ochentas, reorganizando sus discursos y prácticas políticas, agregando nuevas y reagregando algunas antiguas actoras, y modificando tanto su entorno movimientista como el contexto político neoliberal en el que se insertaba. $Y$ aunque el feminismo en protesta era silenciado y reprimido por el neoliberalismo, muchas activistas, y no sólo las autoproclamadas autónomas, no dejaron de manifestarse contra el ascenso de lo que consideraban un feminismo ilegítimo, enfocado en la interlocución con los estados e instancias inter-gubernamentales y en el "advocacy" de políticas públicas, el cual era hegemónico en aquel entonces.

Hoy en día, las fronteras entre las practicas de advocacy y de protesta parecerían ser más permeables, difusas. Por ejemplo, para demostrar el amplio apoyo ciudadano a una acción jurídica que contestaba la constitucionalidad de la criminalización del aborto y que sería debatida en el Supremo Tribunal Federal (STF), se realizó el "Festival pela Vida das Mulheres" en Brasilia en agosto de 2018. El mismo fue organizado por feministas del Frente Nacional pelo Fim da Criminalização de Mulheres e pela Legalização do Aborto y varias redes, ONGs y expresiones feministas autónomas junto al Partido Socialismo e Liberdade (PSOL) y otras agrupaciones de izquierda. Resalto que una acción que antaño hubiera sido vista como esencialmente de "lobby" feminista (para promover una política pública), ahora tomó la forma de festival—una modalidad fruto de la innovación por parte deactivismos más horizontales, como los descritos anteriormente-y no de un encuentro 0 conferencia, esto es, de modalidades "históricas"del campo feminista.

El programa del Festival de cuatro días combinaba practicas típicas de lobby, como el acompañamiento de la audiencia pública en el STF, en la cual varias académicas y activistas feministas intervinieron, así como talleres autogestionados de danza de vientre y pintura indígena, sesiones de poesía, performances del grupo feminista de hip hop Batalhadas Gurias, ruedas de discusión sobre las elecciones de 2018 y sobre el "Intercâmbio Feminista: A luta pelo aborto legal na Argentina, Brasil e Uruguai," y las así llamadas "cirandas" (una danza típica del noreste brasileño), entre muchas otras actividades. Señalando una especie de "solidaridad feminista global 2.0," acciones paralelas fueron organizadas en decenas de ciudades brasileñas para el 8 de agosto, fecha en la que el Senado Argentino votaría el proyecto de ley sobre el aborto-y que llevó a casi dos millones de personas a manifestarse frente al congreso en Buenos Aires a favor de la legalización (Guimarães, 2018).

Los activismos dinámicos e hiper-heterogéneos de los últimos tiempos han producido transformaciones significativas en los discursos así como en las prácticas feministas. La oposición binaria entre "lo especifico" y "lo general", entre lo propiamente feminista y otros asuntos que antes no se consideraban directamente de interés para las mujeres "en cuanto mujeres"- que, como vimos, fue un discurso constitutivo del momento denominado fundacional del feminismo moderno-ya no se sustenta. Tal modelo pierde sentido cuando "negras, indígenas, quilombolas, mestizas, blancas, cis, trans, travestis, no-binarias, lésbicas, heterosexuales, bisexuales, gordas, jóvenes, millennials, trabajadoras rurales, trabajadoras sexuales, madres, estudiantes, personas con 
discapacidades..." se (re)ensamblan para luchar "por la vida, la dignidad y los derechos de todas las mujeres" (Manifesto 8M SC, Florianópolis, marzo 2019) en las ahora frecuentes y multitudinarias movilizaciones feministas, como aquellas realizadas globalmente el 8 de marzo, día internacional de la mujer, hoy transformado en un día de huelgas o paros de mujeres, de momentos de transgresión e intervención político-cultural que articulan a los feminismos con un sinnúmero de otras luchas sociales.

El manifiesto titulado "Más Allá del 8 de Marzo: Camino a una Internacional Feminista," lanzado en marzo de 2019 y viralizado a nivel global, y firmado por veinticuatro intelectuales-activistas notables de Brasil, México, Argentina, Chile, España, Italia y Francia ilustra la indiscutible reformulación de los discursos que hoy caracterizan buena parte de los campos feministas re-compilados por ensamblajes activistas recientes: "Por tercer año consecutivo, mujeres y personas queer en todo el planeta se movilizan contra los feminicidios y contra todas las formas de violencia de género, por la autodeterminación de los cuerpos y por el acceso al aborto seguro y gratuito, por iguales salarios para iguales trabajos, por sexualidades libres, pero también contra los muros y las fronteras, el encarcelamiento en masa, el racismo, la islamofobia y el anti-semitismo, el despojo de las comunidades indígenas y la destrucción de los ecosistemas y el cambio climático..." Las diversas formas/partes de activismo feminista se realinean dinámicamente y muchas se declaran "anti-colonial[es], anti-racista[s] y anti-capitalista[s]", colocándose en "la primera línea de defensa frente al ascenso de la extrema derecha... liderando la resistencia a gobiernos reaccionarios en muchos países" (https://www.internacionalfeminista.org). Aprehender a los feminismos contemporáneos en movimiento nos puede ayudar a realizar ese potencial. 
Revista Punto Género № 11. Junio de 2019

ISSN 0719-0417 / 73 - 102

\section{Bibliografia}

Abers, Rebecca y Tatagiba, Luciana(2015):"Institutional Activism: Mobilizing for Women'sHealth Inside the Brazilian Bureaucracy"en Social Movement Dynamics: New Perspectices on Theory and Practice from Latin America, p. 2016.

Alvarez, Sonia E. (2001): "La Globalización de los Feminismos Latinoarmericanos: Tendencias de los 90 y Desafios para el Nuevo Milenio" en Política Cultural \& Cultura Política: Una Nueva Mirada sobre los Movimientos Sociales Latinoamericanos.

Alvarez, Sonia E. (2009): "Beyond NGOization? Reflections on Latin America." En Development, Vol 52, No 2, p. 172.185

Alvarez, Sonia E. (2014): "Engajamentos Ambivalentes, Efeitos Paradoxais: Movimentos feminista e de mulheres na América Latina e/em/contra o desenvolvimento." En Revista Feminismos, Vol 2, No 1.

Alvarez, Sonia E. y Lima Costa , Claudia (2017): "Turning to Feminisms: Re-visioning Cultures, Power, and Politics in Latin America". En New Approaches to Latin American Studies: Culture and Power".

Alvarez, Sonia E., Friedman, Elisabeth Jay., Beckman, Ericka., Blackwell,Maylei., Chinchilla,Norma.., Lebon, Nathalie., Navarro, Marysa y Ríos Tobar, Marcela (2003):"EncounteringLatin American Feminisms" EnEstudos Feministas, Vol 11, No2, p. 541-575.

Baierle, Sergio. 1992. "Um novoprincípio ético-político: prática social e sujeito nos movimentos populares urbanos em Porto Alegre nos anos 80." Ph.D. Dissertation, Universidade Estadual de Campinas, São Paulo:Brazil.

Baierle, Sergio (1998): "The Explosion of Experience: The Emergence of a New EthicalPolitical Principle in Popular Movements in Porto Alegre, Brazil." In Cultures of Politics/Politics of Cultures: Re-visioning Latin American Social Movements, Boulder, CO: Westview Press.

Banazak, Lee Ann. (2010):The Women's Movement Inside and Outside the State. New York: Cambridge University Press.

Barbosa, Licia Maria de Lima (2013) "Eu me alimento, eu me alimento, força e fé das iabás buscando empoderamento!" Expressões de mulheres negras jovens no hip-hop baiano., Programa Multidisciplinar de Pós-Gradução em Estudos Étnicos e Africanos, Salvador: Universidade Federal da Bahia 
Revista Punto Género № 11. Junio de 2019

ISSN 0719-0417 / 73 - 102

Barrig, Maruja (1998.): "De Cal y Arena: ONGs y Movimiento de Mujeres en Chile. In Feminismos en Chile y América Latina", en Centro de Estudios de la Mujer and Programa Integrado de Estudios de Género, Universidad de Chile. Chile.

Barrig, Maruja. (2001a.) "Introducción (o de Cómo Llegar a un Puerto con el Mapa Equivocado)." enAcosta, Gladys., Barrig, Maruja., Montaño, S., Olea, C y Vargas, Virginia (Edit.): Las Apuestas Inconclusas: El Movimiento de Mujeres y la IV Conferencia Mundial

Barrig, Maruja (2001b): "Latin American Feminisms: Gains, Losses and Hard Times." En NACLA Report on the Americas. Vol 34, No 5, p. 29-35.

Barrios, Luiza y Alvarez, Sonia(2016):"Feminisms and Anti-racism: Intersections and Barriers. An Interview with Luiza Bairros, former Minister of the Special Secretariat for the Promotion of Racial Equality (SEPPIR)", en Meridians: feminism, race, transnationalism. Vol 14, No 1, p. 50-69.

Bento, Maria Aparecida Silva (2002): "Branqueamento e Branquitude no Brasil." En Psicologia social do racismo--estudos sobre branquitude e branqueamento no Brasi,. Petrópolis, RJ: Vozes. P. 5-58

Bernal, Angélica Maria (2017): Beyond Origins: Rethinking Founding in a Time of Constitutional Democracy. New York: Oxford University Press.

Bourdieu, Pierre (1993): The Field of Cultural Production. London: Polity Press.

Buarque de Holanda, Heloisa. (2018):Explosão Feminista: Arte, Cultura, Política e Universidade. Rio de Janeiro: Companhia da Letras.

Caldwell, Kia Lilly. (2007). Negras in Brazil: Re-visioning Black Women, Citizenship, and the Politics of Identity. New Brunswick, NJ Rutgers University Press.

Cardoso, Claudia Pons (2012): Outras Falas: Feminismos na Perspectiva de Mulheres Negras Brasileiras. Doctoral Dissertation, Universidade Federal da Bahia, Salvador, Bahia.

Cardoso, Claudia Pons (2016):"Feminism from the Perspective of Afro-Brazilian Women" en Meridians: feminism, race, transnationalism. Vol 14, No 1, p. 1-29

Carneiro, Suely (1995): "Gênero, Raça e Ascensão Social." En Estudos Feministas, Vol 3, No 2, p. 544-552. 
Revista Punto Género № 11. Junio de 2019

ISSN 0719-0417 / 73 - 102

Carneiro, Sueli (1999): "Black Women's Identity in Brazil." enReichmann, RebeccaRace (Edit): In Contemporary Brazil: From Indifference to Inequality, p. 217-228,University Park, PA: Penn State University Press.

Carvalho, Priscila (2018): "A Produção do Transnacional: Compilações da Agricultura Familiar e CamponesanaContag e no MPA"Tesis de doctorado. Brasil:Universidade Federal de Minas Gerais.

Castro, Mary García (2001): "Engendering Powers in Neoliberal Times: Reflections from the Left on Feminisms and Feminisms." , en Latin American Perspectives, Vol 28 No 6, p. 17-37.

Clarke, John., Bainton, Dave.,Lendvai, Noém y Stubbs, Paul (2015):Making Policy Move: Towards a Politics of Translation and Assemblage. Bristol: Policy Press.

Conway, Janet M., Osterweil, Michal yThorburn ,Elise. (2018): Theorizing Power, Difference and the Politics of Social Change: Problems and Possibilities in Assemblage Thinking, enStudies in Social Justice, Vol12, No 1, p. 1-18.

Costa, Claudia de Lima. /2014): "Equivocação, tradução e interseccionalidade performativa: observações sobre ética e prática feministas descoloniais."en Obarrio, Juan y Sierra, Marta (Edit): Genologías e Memorias Poscoloniales en América Latina: Escrituras fronterizas desde el Sur, p. 260-293. Buenos Aires: Ediciones Godot.

Do Carmo, Íris Nery (2018):“O Rolê Feminista: Autonomia, Horizontalidade e Produção do Sujeito no Campo Feminista Contemporâneo" Tesis de doctorado. Brasi:I Universidade Estadual de Campinas.

Doimo, Ana Maria (1995): A vez ea voz do popular: movimentos sociais e participação política no Brasil pós-70. Rio de Janeiro: Relume-Dumará/ANPOCS.

Dowbor, Monika y Swako, José(2013) "Respeitável Público...Performance e organização dos movimentos antes dos protestos de 2013." Novos Estudos Cebrap, Vol,97 (November, p. 43-55.

Enke, Anne [Finn] (2007): Finding the Movement: Sexuality, Contested Space, and Feminist Activism. Durham, NC: Duke University Press.

Escobar, Arturo (2008):Territories of Difference: Place, Movements, Life, Redes. Durham, NC: Duke University Press.

Ferreira, Gleidiane de S (2013) "Feminismo e Redes Sociais na Marcha das Vadias no Brasil", en Revista Ártemis, Vol XV, No 1, p. 33-43. 
Revista Punto Género № 11. Junio de 2019

ISSN 0719-0417 / 73 - 102

Fligstein, Neil y McAdam, Doug (2012)A Theory of Fields. New York: Oxford University Press.

Gaviola, Edda, Eliana Largo, and Sandra Palestro (1994) Una Historia Necesaria. Mujeres en Chile: 1973-1990. Santiago de Chile: Akí \& Aora Ltda.

Godinho, Maria Berenice (1998): "Mulheresna CUT: umnovoolhar sobre o sindicalismo", en Borda, Angela., Faria ,Nalu y Godinho ,Tatau (Edit.): Mulher e Política: Gênero e feminismo no Partido dos Trabalhadores, , p. 209-224. PerseuAbramo.

Gomes, Carla (2018):"Corpo, Emoção e Identidade no Campo Feminista Contemporâneo Brasileiro: A Marcha das Vadias do Rio de Janeiro". Tesis de doctorado. Brasil: Universidade Federal do Rio de Janeiro.

Gonçalves, Eliane., Freitas, Fátima y Oliveira, Elismênnia(2013): "Das Idades transitórias: As "jovens" no feminismo brasileiro contemporâneo, suas ações e seus dilemas." En Revista Feminismos. No 1

Gomes, Carla, and Sorj, Bila(2014): "Corpo, Geração e Identidade: A Macha das Vaida no Brasil", en Revista Sociedade e EstadoVol 29, No2, p. 433-447.

Gonçalves, Eliane y Pinto, Joana (2011): "Reflexões e problemas da 'transmissão' intergeracional no feminismo brasileiro." Cadernos Pagu, p. 36:25-45.

Guimarães, Paula (2018):Brasil se mobiliza para o debate sobre a descriminalização do aborto na Suprema Corte.Portal Catarinashttp://catarinas.info/brasil-se-mobiliza-para-odebate-sobre-descriminalizacao-do-aborto-na-suprema-corte/; accedido 22 marzo 2019.

Guzzo, Morgani (2019): "Corpos e Campos Plurais: Os Feminismos das Marchas das Vadias no Brasil"Tesis de doctorado. Brasil: Universidade Federal de Santa Catarina.

Hemmings, Claire (2011):Why Stories Matter: The Political Grammar of Feminist Theory.Durham, NC: Duke UniversityPress. Kindle edition.

Hermida, Viviane (2018):" PorNós, Pelas Outras, Por Mim: A Política Feminista da Marcha das Vadias Recife"Tesis de doctorado. BrasiL:Universidade Federal da Bahia.

Hermida, Viviane. (2014):Marcha das Vadias: Reflexõesiniciais sobre a trajetória de umaexpressão dos feminismos no Brasil:Ensayoinédito

Hewitt, Nancy (2010):No Permanent Waves: Recasting Histories of U.S. Feminism. New Brunswick, NJ: Rutgers University Press. 
Jaquette, Jane S y Wolchik ,Sharon ( 1998):. Women and Democracy: Latin America and Central and Eastern Europe. Baltimore: Johns Hopkins University Press.

Lebon, Nathalie (1998): "The Labor of Love and Bread: Volunteer and Professionalized Activism in the São Paulo Women's Health Movement."." Ph. D.Presentacipón en , University of Florida.

MacFarlane, Colin (2009):"Translocal Assemblages: Space, Power and Social Movements" enGeoforum, Vol 40, No. 4, p. 561-567.

Magrini, Pedro y Lago, Mara(2013):"A incorporação de lutastransversais pelo MovimentosTrabalhadoresRuraisSem Terra (MST)" en Mal Estar e Sociedade, No 10, p. 13-37.

Maia, Suzana (2012):“'Identificando a branquidade inominada: corpo, raça e nação nas representações sobre Gisele Bündchen na Mídia Transnacional"Cadernos PagubarrNo 38 , p. 309-341.

Marques, Gabriela. 2013. Cena Anarcopunk: Resistências feministas em um "espaço masculino" (1990-2012). Tesis de doctorado, Brasil: Universidade Federal de Santa Catarina.

Martello, Laura (2015):“Tensões e DesafiosnaConstrução de Espaços e Encontros entre Feministas Jovens Autonomistas no Contexto Brasileiro e Latinoamericano (20112014)"Ph.D. Dissertation. Federal University of Minas Gerais.

Matos, Marlise (2014) "A Quarta onda feminista e o Campo crítico-emancipatório das diferenças no Brasil: entre a destradicionalização social e o neoconservadorismo político." ANPOCS, Caxambú, MG, 2014.

Matos, Marlise y Alvarez, Sonia E.(2018):" As CNPMs e a configuração do campo feminista: Sidestreaming, Mainstreaming, e o 'feminismo de estado participativo," en Matos, Marlise y Alvarez, Sonia (Edit): In Quem São as Mulheres das Políticas para as Mulheres no Brazil? Vol. II, ExpressõesFemnistasnasConferênciasNacionais de Políticas para as Mulheres,.São Paulo: Zouk.

McGlazer, Ronnie, (2018)“Special Section: Transnational Feminist Strikes and Solidarities", enCritical Times: A Journal of the International Consortium of Critical Theory Programs. Vol. 1, No. 1.https://ctiournal.org/index.php/criticaltimes. 
Revista Punto Género № 11. Junio de 2019

ISSN 0719-0417 / 73 - 102

Moreira, Núbia Regina (2011): A organização das feministas negras no Brasil. Vitória da Conquista, Bahia: Edições UESB.

Müller, Martin (2015):" Assemblages and Actor Networks: Rethinking Socio-material Power, Politics and Space" enGeography Compass, Vol 9, No1, p. 27-41.

Murdock, Donna (2008):When Women Have Wings: Feminism and Development in Medellín, Colombia. Ann Arbor, Ml: University of Michigan Press.

Name, Leo, and Zanetti, Julia (2013):"Meu Corpo, Minhas redes: A Marcha das Vadias do Rio de Janeiro"Anais da ANPUR.

Nail, Thomas (2017):“What is an Assemblage?" en SubStance, Vol 46, No 1, p. 21-37.

Olea Mauleón, Cecilia (1998):Encuentros,(des) encuentros y búsquedas: El movimiento feminista en América Latina. Lima: Ediciones Flora Tristán.

Olea Mauleón, Cecilia y Vargas, Virginia (1998): "Los Nudos de la Región", en Olea, Cecilia (Edit.): Encuentros, (Des)Encuentros y Búsquedas: El Movimiento Feminista en América Latina,. Lima: Ediciones Flora Tristán.

Pedro, Joana., Scheibe, Cristina ., Wolff, and Veiga, A. M. (2011):Resistências, gênero e feminismos contra as ditaduras no Cone Sul. Florianópolis: Editora Mulheres.

Perez, Olívia y Ricoldi, Arlene (2018). "A Quarta Onda do Feminismo? Reflexões sobre Movimentos Feministas Contemporâneos." ANPOCS, Caxambú, MG, 2018.

Pinto, Céli Regina Jardim. 2003. Uma história do feminismo no Brasil. São Paulo: Editora Fundação Perseu Abramo.

Piza, Edith (2000): Branco no Brasil? Ninguém Sabe, NinguémViu. En Guimarães, Antonio Sérgio Alfredo y Huntley, Lynne Walker (Edit): Tirando a Máscara: Ensaios sobre o Racismo no Brasl, p. 97-126. São Paulo: Paz e Terra.

Ribeiro, Matilde (1995): "Mulheres negras brasileiras: de Bertioga a Beijing", en Revista Estudos Feministas, Vol 3, No 2. p. 446-458.

Ribeiro, Matilde (2006): "O feminismo em novas rotas e visões." enRevista de Estudos Feministas, Vol 14, No 3, p. 801-811.

Ríos Tobar, Marcela., Godoy Catalán., Lorena y Guerrero Caviedes, Elizabeth(2003):Un nuevo silencio feminista? La transformación de un movimiento social en el Chile postdictadura. Santiago: Centro de Estudios de la Mujer; Editorial Cuarto Propio. 
Revista Punto Género № 11. Junio de 2019

ISSN 0719-0417 / 73 - 102

Riquer Fernández, Florinda (2005): Del Movimiento Feminista a la Institución: Una historia que aún no puede contarse? Veracruz, México: Universidad Veracruzana.

Rodrigues, Cristiano Santos y Máximo Prado, Marco Aurelio(2010): "Movimento de Mulheres Negras: trajetória política, práticas mobilizatórias e articulações com o estado brasileiro " enPsicologia \& Sociedade, Vol 22, No 3, p. 445-456.

Saads, Leila y Nascimento, Líbia Rany Oliveira (2013): "Entre mulheres nômades: reflexões sobre o "sujeito feminista" e o diálogo entre diferentes na Marcha das Vadias DF" ,en Anais do Congresso - Fazendo Gênero, Vol 10.

Sader, Eder (1988): Quandonovospersonagensentraram em cena: experiências, falas e lutas dos trabalhadores da Grande São Paulo (1970-80). São Paulo: Paz e Terra.

Santos, Sônia Beatriz (2009) "As ONGs de mulheres negras o Brasil" en Sociedade e CulturaVo 12, No 2, p. 275-288.

Schumaher, Maria Aparecida y Vargas, Elisabeth (1993): "Lugar no governo: Álibi ou conquista?" en Revista Estudos Feministas, Vol 1, No 2, p. 348-365.

Schwarz, Roberto y Arantes, Paulo (2013):Cidades Rebeldes passe livre e as manifestações que tomaram as ruas do Brasil. São Paulo: Boitempo.

Silva, Berenice Gomes da (2008): A Marcha das Margaridas: resistências e permanências. Dissertação (Mestrado). Departamento de Pós-Graduação em Sociologia: Universidade de Brasília.

Singer, André (2014): "Rebellion in Brazil: Social and Political Complexion of the June Events" en New Left Review, No 85, p.19-37.

Slovik, Liz (2009): Aquí Ninguém é Branco. Rio de Janeiro: Aeroplano.

Souza, Vera Cristina (2000). "Miomatose em Negras e Brancas Brasileiras: Semelhanças e Diferenças" en Jornal da Rede Saúde, No 23, p.20-23.

Teles, Maria Amélia de Almeida (2017):Breve História do Feminismo no Brasil e Outros Ensaios. São Paulo: Alameda.

Thayer, Millie (2010):Making Transnational Feminism: Rural Women, NGO Activists, and Northern Donors in Brazil. New York: Routledge.

Vargas, Virginia (2000): "Institucionalidad Democrática y Estrategias Feministas en los Años 90: El Estado, las Mujeres y la Política a través de la Historia Latinoamericana" en 
Revista Punto Género № 11. Junio de 2019

ISSN 0719-0417 / 73 - 102

De Poderes y Saberes: Debates sobre Reestructura Política y Transformación Social, Memória del II Seminario Regional, edited by Development Alternatives with Women for a New Era (DAWN) and Red de Educación Popular Entre Mujeres de América Latina y el Caribe (REPEM). Montevideo, Uruguay: DAWN; REPEM.

Vargas, Virginia, and Olea Mauleón, Cecilia (1998): "Roads to Beijing: Reflections from Inside the Process." En Vargas, Virgina (Edit): Roads to Beijing: Fourth World Conference on Women in Latin America and the Caribbean. . Lima; Santafé de Bogotá; Quito: Ediciones Flora Tristán; UNICEF; UNIFEM.

Vargas, Virginia, and Olea, Cecilia(1999): "An Agenda of One's Own: The Tribulations of the Peruvian Feminist Movement." en Yuval-Davis, Nira y Werbner Pnina (Edit.): Women, Citizenship and Difference, p. 246-262. London: Zed Books 